\title{
Sabores y saberes: de la carne a la palabra. Una relectura de Digo lo que amo (1976), de Abigael Bohórquez
}

\author{
Savor and knowledge: from flesh to word. \\ A re-reading of Abigael Bohórquez's Digo lo que amo (1976) \\ Alejandro Ramírez Arballo \\ The Pennsylvania State University, Estados Unidos de América \\ aar14@psu.edu
}

Resumen:

La obra de Abigael Bohórquez ha encontrado a últimas fechas, sobre todo a raíz de la publicación de las obras completas por parte del Instituto Sonorense de Cultura y editadas por el doctor Gerardo Bustamante Bermúdez, nuevos lectores y, por tanto, ha suscitado nuevos intereses. Esto es altamente beneficioso porque entraña la posibilidad de leer la obra abigaeleana más allá de los lugares comunes que la crítica, muchas veces panfletaria y reduccionista, ha impuesto durante los últimos años. En concordancia con esta idea, el presente artículo busca acercarse a Digo lo que amo (1976), un libro fundamental en el corpus del poeta sonorense, buscando realizar una hermenéutica basada en la variante "carnal", propuesta por el filósofo irlandés Richard Kearney. De esta manera, el cuerpo lírico, desplegado en la poesía de Bohórquez se convierte en un órgano capaz de mediar entre la conciencia y el entorno del hablante; entonces la apropiación del mundo del intérprete deja de ser exclusivamente intelectual para convertirse en un acto, en una experiencia rica, compleja y, sobre todo, dadora de sentido. 
Palabras clave:

Abigael Bohórquez, hermenéutica carnal, poesía, sentido, queer.

Abstract:

Abigael Bohórquez's work has recently found new readers, especially because of the publication of his complete works, edited by Dr. Gerardo Bustamante Bermúdez, by Instituto Sonorense de Cultura. This volume has in turn aroused new interest in the writer. This is highly beneficial because it entails the possibility of reading the Abigaelean work beyond the common places that the critics, many times pamphleteers and reductionists, have imposed during the last years. In accordance with this idea, this article approaches Digo lo que amo (1976), a fundamental book in the corpus of the Sonoran poet, seeking an interpretation based on the "carnal" variant proposed by the Irish philosopher Richard Kearney. In this way, the lyrical body deployed in Bohórquez's poetry becomes an organ capable of mediating between the consciousness and the environment of the speaker. Thus, the appropriation of the interpreter's world ceases to be exclusively intellectual to become an act, a rich, complex and above all meaningful experience.

Keywords:

Abigael Bohórquez, Carnal Hermeneutics, poetry, meaning, queer.

DOI: https://doi.org/10.36798/critlit.vi20.316

Recibido: 26 de septiembre de 2019 Aceptado: 25 de febrero de 2020 


\section{Preliminar}

La poesía de Abigael Bohórquez se caracteriza, entre otras cosas, por un notable dominio de las formas poéticas. ${ }^{1}$ Se trata de una obra rigurosa y vital que alcanza momentos de auténtica brillantez en los que la pasión existencial del autor destaca por su contundencia emotiva y originalidad, así como por la riqueza de sus registros verbales. Más allá de esta impresión, conviene adentrarse en el estudio sistemático de su obra para comprender de manera suficiente cuáles son los mecanismos que el autor utiliza para alcanzar — como decididamente lo hace - tan grandes cotas de expresión humana y literaria. Creo que la mejor manera de homenajear la vida y la obra de un autor que se admira es tratando de comprender aquello que ha escrito. No olvidemos que comprender algo es participar voluntariamente de eso que se busca entender.

En Digo lo que amo, el autor sonorense declara urbi et orbi la encarnación de su amor. Da muestra de una actitud desafiante al articular la defensa de sí mismo, es decir, la de alguien que se siente bajo acoso y que reacciona con un gesto de airado envanecimiento no exento de humor y acidez: lo reprimido se visibiliza con estridencia en estas páginas; contra el silencio impuesto, la emancipación de las palabras. Decir el amor que se siente es reclamar la necesaria libertad, esa que los amantes "normales" o legítimos disfrutan siempre, sin tener que padecer el juicio por parte de una sociedad que fustiga cualquier desviación erótica y sentimental que no se corresponda con la heterosexualidad.

${ }^{1}$ Quizás una de las señas de identidad más visibles en este autor sonorense es la reapropiación —-muchas veces lúdica o humorística- de las estructuras líricas tradicionales. En Digo lo que amo, Bohórquez juega con métricas de arte menor o popular y de arte mayor, como el soneto endecasílabo; además, desde un punto de vista léxico-estilístico, es capaz de reproducir con maestría el estilo siglodeoresco y de la poesía prehispánica. No escasean las intertextualidades bíblicas, los juegos verbales como el calambur o calembur y el humor como estrategia constante a lo largo de estos poemas. 
Para conseguir sus objetivos en este libro, Bohórquez construye un yo poético que enuncia desde los sentidos, privilegiando sobre todo una vida que se siente, que pasa por la propia carne y que despierta en los deleites que el encuentro con el amado le provee. Al mismo tiempo, es un yo crítico, acérrimo, contumaz, que denuncia la hipocresía social, la incongruencia de un estado de cosas evidentemente injusto; por ejemplo, es capaz de montar el artificio satírico, lo que presupone la existencia de una inteligencia aguda y un compromiso explícito con el escarnio reivindicativo. Ciertamente, en el enunciante coexisten la inteligencia y la sensibilidad, la agudeza de ingenio y el disfrute absoluto de los sentidos. Aquí creo necesario hacer una aclaración para evitar que el lector anticipe un análisis exclusivo de los aspectos emotivos o sensuales del texto. La hermenéutica carnal, que en este ensayo guía teórica y reflexivamente mis pasos, no presupone que la razón sea algo opuesto a la pasión emotiva; por el contrario, asume que esta última es necesaria como parte del proceso de comprensión del ser propio, el de los demás y el de las cosas que pueblan el mundo: no se comete el error de asumir que la conciencia del ser humano se encuentra desvinculada de su condición material.

Para la hermenéutica carnal, la interpretación no es solamente un asunto verbal sino que implica incorporar la sensación física, porque nosotros no tenemos un cuerpo sino que somos un cuerpo. Para esta clase particular de hermenéutica, el sentido no solo es la sensación sino la dirección y la lógica misma de la existencia. ${ }^{2} \mathrm{Si}$ con Heidegger —y después con Gadamer ${ }^{3}$ — se habla del giro lingüístico trascendental de la hermenéutica, con Kearney (y antes con los representantes de la fenomenología, Husserl y Merleau Ponty) podemos y debemos hablar de un giro sensual en la filosofía de la interpretación. El ser humano no solo "comprueba" el mundo en lo

2 Aunque sin llegar a abordar con claridad la idea del giro sensual, Gadamer apunta: "La palabra muerta debe resucitar en un lenguaje vivo". (Verdad y método II 279)

3 “Comprender es el carácter óntico original de la vida humana misma” (325). 
que toca sino que al mismo tiempo es tocado por la realidad material y por la presencia del otro que, como ella o como él, es un ser sintiente que deambula por el mundo buscando una razón de ser y un rumbo vital. La mano que toca es al mismo tiempo tocada, algo que no sucede con otros sentidos, como la vista, el olfato y el oído, tradicionalmente considerados superiores. Cuando degustamos también experimentamos esta relación de ida y vuelta, que nos ayuda a comprender no solo lo que el mundo de los entes y seres humanos es, sino lo que nosotros mismos somos. No es casualidad que en Digo lo que amo abunden — como se verán— las referencias al tacto y el gusto: los amantes se tocan y se devoran interminablemente.

Resumiendo, es claro que mi lectura de Digo lo que amo se focaliza en la construcción sensible del mundo que el yo poético realiza, porque con esta estrategia el autor legitima de un modo vicario su amor, que no es una idealización sino una acción y una presencia, un gozo común de los que deciden entregarse a los juegos de la pasión erótico-afectiva. Puede hablarse incluso de una sabiduría del cuerpo, lo que implica el cumplimiento radical de la creatividad amatoria. Con esto me refiero a la relación eros-logos: la sexualidad bruta trastocada por la inteligencia que construye y elabora, dando sentido de relato al encuentro sexual; la fisiología trascendida por la voluntad erótica de creación y disfrute. De este modo, la sexualidad se transforma en un lienzo sobre el cual el ser humano despliega un diálogo sensorial, un vínculo interpersonal de gran potencia psíquica y espiritual. El poema crece desde el cuerpo, se incuba en él:

As soon as one has breath, one has a resonance of the ribcage, a link with the mouth (which can be blown across from the side like the top of a bottle to produce sound), an then from the mouth to the ears, whereby the body becomes a sounding device, an instrument or poem growing more, not less, articulate under stress. To get sound out, there has got to be some pressure, and pressure cannot be found in the kingdom of the innocent. (Smith 166) 
El poeta reacciona y salta, es hijo de su voluntad de ser y crear en el mundo. En el caso concreto de Digo lo que amo, la presión que fuerza el canto es evidente en sí misma: la marginalización de una sensibilidad personal.

Decir lo que uno ama es un acto de libertad y celebración al que no se puede renunciar sin mutilar la propia vida, sin renunciar, por cobardía o por torpeza, al sagrado derecho de construirnos y reconstruirnos cuantas veces sea necesario, y aun más, de abrirnos al otro para tomar y ser tomados. Solo entonces, cuando hemos sido capaces de conseguir ese diálogo no verbal es que somos capaces de alcanzar una conciencia plena de nuestro ser en el mundo. Conviene recordar un concepto acuñado por el profesor Carlos Bousoño, el de la unicidad:

Hemos visto que toda realidad anímica es un complejo de elementos conceptuales, sensoriales y afectivos que forman una síntesis espiritual, un todo que difiere de la suma de sus partes. De los tres elementos que lo constituyen, solo uno puede ser común a varios individuos: el conceptual. Los otros dos cambian siempre con el sujeto. (44)

La poesía pues, al menos en su raíz de experiencia personalísima — sensorial y amatoria_- es intransferible, pero sin ese espacio de intimidad y libertad del poeta no sería posible construir una obra tan original como auténtica, como en el caso del poeta de Sonora. $\mathrm{Al}$ decir esto me estoy refiriendo a la radical subjetividad del hablante poético. El cuerpo, que no se nos olvide, es un profundo pozo de conocimiento, puesto que a través de él nos relacionamos con el mundo de la materia, con la realidad que simbolizamos a través de las construcciones textuales.

\section{Tocar es conocer}

En el poema inaugural de este libro, llamado "Primera ceremonia", observamos un cuadro realmente hermoso y significativo. El hablante poético contempla al amado, lo recorre con la mirada y lo 
nombra, lo honra con epítetos dulcísimos y lo palpa para corroborar que es real, que existe. La escena conmueve y es iluminadora: la comprensión del amor es un acto de admiración en el que lo observado no es algo dado sino algo que se da y actualiza en el reconocimiento sensible de su existencia: no basta ver, además es necesario observar, contemplar y desear. Pensemos que ese yo poético busca comprender el cuerpo del que ama: se fusiona con él al llamarlo, se reconoce en él al indagar en sí mismo, como un inventario de profundísimas sensaciones personales: el abanico entero de la dulzura y estremecimiento que lo habita. Se trata de un diálogo callado, una exploración de ese cuerpo que es pura geografía, pero que despierta en el roce de piel a piel para convertirse en territorio conquistado. ¿Qué esfuerzo conceptual, qué lenguaje sería capaz de contarnos estos encuentros secretos? Me queda claro que la poesía - icono y símbolo perfecto- es el camino elegido porque reproduce en sí misma el ritmo y el acoplamiento significativo del encuentro carnal, porque al cantar transforma un mundo de caras y cosas ignoradas, porque muestra y oculta siempre. Son las palabras las que nombran y al nombrar se apropian de ese ser rendido con el que el hablante poético yace: el verso funge, pues, como amorosa invasión del otro ser. Decir lo que se ama es declarar derechos de posesión y dominio en el amado; recordemos que una y otra vez los que se aman utilizan la expresión posesiva "mi amor" para referirse el uno al otro. La idea de salir del cuerpo, presente en esta tradición fenomenológica y hermenéutica que va de Husserl a Gadamer, entraña el esfuerzo personal de incorporación a la vida. Kearney afirma:

Body and flesh are thus distinguished through the radicality of an originary phenomenological dualism. The body lacks the power to make manifest; it has to seek its manifestation in the world outside-of-oneself and is thus constituted as a mundane body. (129)

Nombrar el mundo es darle forma, salir de uno mismo y acotar la entropía bajo el principio del sentido que deviene en la frase y, en este caso, en el verso. El cuerpo es hijo de la voluntad y, en este 
caso, de la voluntad amatoria. La carne, por su parte, es fisiología bruta: vida desprovista de humanidad.

En cuanto a este poema, puede verse cómo es que la contemplación, lejos de permanecer en el goce personal y platónico de las palabras, busca además la intimidad de las caricias y finalmente el goce radical del acoplamiento: "Aparentas dormir / y una sonrisa esplende tus pupilas; /quedo sin mí . . . cuando mis manos desdoblan su pobreza / y tocan tus cabellos dóciles, como el agua /y me tiendo a tu lado ... Tómame ... Hiendes la oscuridad, / y adentro: / llueves" (331-2). Es una relación doble, que entraña tanto palabras como roces: la renuncia a la carne y la obstinación de lo verbal mutila nuestra capacidad de comprensión de las cosas. Al transformar la experiencia en poesía la convertimos en otra cosa y hacemos del acontecimiento carnal un mero referente; la palabra instaura un orden distinto. Lo que pensamos, es decir, lo que verbalizamos, pasa por nuestros sentidos, alimenta y orienta el mundo interior y abstracto de nuestras cavilaciones. La reflexión sobre el mundo material entraña un trasunto sensual que organiza el pensamiento que creamos en torno a un objeto experimentado. En el caso de las relaciones interpersonales, no podemos olvidar que el otro es, además de cuerpo, palabra que se abre a nosotros como carne y como voz, lo que hace que nuestra relación con los demás sea única e incomparable: no existe estímulo más complejo y rico que compartir el mundo o un instante con alguien. En el breve poema "Reconstrucción del lecho" se lee:

\author{
en esta cama fueron \\ las tentaciones. \\ yo tenté.
}

tú tentaste.

ustedes, qué!! (336)

Más allá de la evidente crítica a los censores morales de la homosexualidad, el poema señala implícitamente algo que concierne a estas breves reflexiones teóricas: la experiencia sensual dialógica cierra las puertas para los demás, para quienes no participan, es decir, 
para quienes no tocan ni son tocados. Los cuerpos entrelazados se corresponden en modo absoluto, se separan, para decirlo metafóricamente, del resto del mundo y se ocupan de su experiencia de gozo compartido. ¿Qué papel desempeñan las palabras en estos momentos de trance deleitoso? Creo que uno muy secundario: expresiones sueltas que tienden al gemido. En todo caso, es tiempo después, cuando se busca la reconstrucción placentera de la experiencia sexual cuando las palabras se vuelven más y más importantes, hasta convertirse en verdaderos vehículos de reapropiación y reelaboración de la experiencia.

Ricœur afirma en relación a lo metafórico como condición esencial de lo poético: "A metaphor, in short, tells us something new about reality" (Interpretation Theory 53). Por otro lado, Norman Brown va más allá y roza lo esotérico al preguntarse retóricamente: "Why are the mysteries unpunishable? First because they cannot be put into words, at least not the kinds of words which earned you your Phi Beta Kappa keys. Mysteries display themselves in words only if they can remain concealed; this is poetry, isn't it? (9) No hay memoria sin lenguaje, pero no hay misterio sin limitación de ese lenguaje. La poesía recupera y simboliza, pero el precio por ello es la destrucción del instante material concreto; en este caso se trata del goce carnal. Esto hace que en todo poema la experiencia solo se encuentre presente de manera residual, como calco o trasunto.

Por todo lo anterior, es pertinente afirmar que la poesía tiene una función trascendente. Se trata de un discurso que vincula analógicamente lo referencial y lo experiencial, que ha de dejar siempre una huella psíquica en nosotros. Imaginar, por ejemplo, el sabor del limón nos hace reaccionar fisiológicamente salivando en exceso; la imagen en sí misma es parte de nuestra conciencia al ser recordada: la poesía y el arte en general forjan de una manera única este tipo de memorias y enriquecen de este modo nuestra concepción de la vida. De esto se puede derivar lógicamente que la experiencia poética nos vuelve más sensibles como espectadores del mundo, abriendo canales de comprensión sensorial, enriqueciéndolos y hasta cierto punto educándonos en el arte de sentir la vida. 
Richard Kearney se refiere a la piel ${ }^{4}$ como un "Hermes", es decir, como un mediador entre nosotros y el mundo: en esa zona de encuentro es que se unen las sensaciones y las palabras; la sensación antecede la enunciación. En conexión con esto, en esta obra de Bohórquez el tacto encarna esa posibilidad de transmisión de sentido, y aun de creación: "Tiendo una mano: existes". (332) Lo que se toca se vuelve real y merece entonces el canto que lo nombra. El placer anticipado —o recordado— es fuente de la imaginación. De nuevo Ricœur:

Our Task here is to rediscover the essential function of pleasure and of the body in general with respect of willing. This is why we must again return from the seductive and seduced imagination to the temptation which is not yet fault, though it is an invitation to fault. The temptation is only the point of least resistance presented by human affectivity to the invasion of the vertigo. Imagination is not structurally the seat of calamities; by its nature, the will is stronger than the need brought to light by imagining a pleasure. (Freedom and Nature 103)

Según el filósofo francés, del maridaje entre imaginación y tentación deviene la culpa, pero muy lejos de todo remordimiento, el yo poético en Digo lo que amo se envanece en el ciclo del deleite anticipado, vivido y posteriormente recordado. La voluntad no es de represión sino todo lo contrario, de expansión y gozo que se proyectan al infinito.

La vuelta a la carne no pretende desmontar la idea del lenguaje como medio de comprensión de la realidad; por el contrario, lo que se busca con ello es una incorporación más que una sustitución. Las sensaciones, que como hemos visto son mediadoras y siempre anteceden el discurso, enriquecen el fascinante mundo de la com-

4 "Like Hermes, it is forever mediating and messaging between inside and outside, self an other, human and more-than-human. Tangible flesh is constantly a medium of transition. It is always on". (103) 
prensión: no atender esta dicotomía es siempre una pérdida. Las sensaciones revelan un mundo y posibilitan el juicio prudente sobre ese mundo. ${ }^{5}$ Entre la univocidad de lo escrito y la equivocidad de lo sensible es menester encontrar una condición analógica que haga coincidir el equilibrio y el dinamismo, una condición proporcionada que nos sirva no solo para nombrar lo que sentimos sino para sentir lo que decimos, en otras palabras, para ser plenamente humanos, plenamente personas.

\section{E1 documento lírico}

Existe en Digo lo que amo una evidente condición formal: se presenta en nueve de sus veinte poemas como un texto legal, como una suerte de documento que se constituye en un acto de defensa poético-satírica de ese yo enunciante que se atreve a confesar la forma no convencional de sentir, vivir y decir el amor. Esto se encuentra enmarcado por el epígrafe y la dedicatoria, en los que se refiere al escritor irlandés Oscar Wilde, condenado a trabajos forzados por sodomía. ${ }^{6}$ Decir el amor, pues, es defenderse, enfrentar la

${ }^{5}$ Recordemos que "tener tacto" es una expresión que alude no al sentido material sino a la sutileza en el trato, al carácter prudencial de una persona y, en última instancia, a su sabiduría.

6 "OSCAR: ¿Creer que estoy aquí por mis relaciones con algunos profesionales del vicio? Pero si Inglaterra entera está llena de hombres así. Tan sólo al día siguiente de mi condena, esos hombres se han sentido amenazados por primera vez. Los hay militares, ministros, nobles... ¿acaso condenaron al Duque de Clarence de la Familia Real Inglesa? Si yo no hubiera conocido a Douglas, estaría libre y me hubieran permitido el trato con los Parker, los Wood, los que venden su amor en todos los Savoy del mundo entero. Lo que Inglaterra no me perdona, son los vicios que encubre con su hipocresía, no me perdona que en mí sea un gran amor. Por eso se han desatado las fuerzas secretas para marcarme con el fuego y el ridículo. Cuando un amor como el mío desafía la tradición burguesa, se le castiga a trabajos forzados.

FRANK: El único amor legítimo, Oscar, es el que une a un hombre y a una mujer. 
agresividad pasiva o manifiesta de un amplio sector de la sociedad que considera la homosexualidad una práctica y condición humanas sujetas a castigo, o por lo menos a sospecha. Por esto último no me refiero, debo enfatizarlo, a un mero desdén o estigmatización, sino a un riesgo patente de agresión física o verbal, de acción violenta dirigida, lo que enmarca la defensa lírica de la práctica amorosa homoerótica en una situación de riesgo y límite.

Es importante hacer ver que la voz poética no desconoce los recursos de la ironía y el sarcasmo, elementos del discurso que emplea en la configuración caricaturesca y satírica: su defensa es verbal e implica ridiculizar a los agresores, desenmascararlos para romper la ilusión de su poder. Al recurrir al escarnio, la voz poética está haciendo patente lo grotesco de la visión del mundo que manifiestan sus acusadores. Se trata de una acción de resistencia poética y política que asume la declaración de una identidad propia sin temor a las consecuencias punitivas de una sociedad heteronormativa. Al respecto, el profesor Bustamante afirma en su edición de Digo lo que amo:

Abigael Bohórquez ejerce el poder de la poesía al deconstruir los códigos patriarcales que instauran los binarismos heterosexuales para, desde el mismo espacio de poder, excluir y prohibir otras formas de amar y ejercer la sexualidad. Su voz se vuelve poder cuando registra su apreciación y experiencia amorosa. (13)

De este modo, la poesía de Bohórquez es más que una confesión o testimonio, es una estrategia de defensa: las palabras vuelven visible para todos, para la conciencia del colectivo humano, una realidad particular, privada y tradicionalmente condenada a la marginalidad de lo cerrado. El cerrojo de la condena es destrozado por la vociferación del poeta, enardecido y puntual en sus acusaciones contra la simulación imperante. En este caso la libertad es tomada por

OSCAR: Te concedo que para ti no exista más amor que ese, pero no me lo digas a mí, que me he ofrecido en holocausto.” (en Bohórquez 327). 
asalto en un acto reivindicativo de resistencia poética frente a las funestas prácticas de la segregación y el desprecio. Lo anterior puede parecer exagerado, pero es imperativo considerar el contexto jurídico, social y religioso de la época en que el libro fue publicado; pensemos, por ejemplo, que apenas habían transcurrido tres años desde que la American Psychiatric Association retiró la homosexualidad de su Manual Diagnóstico y Estadístico de Trastornos Mentales. Esto quiere decir que en el imaginario social aún persiste por esos años la identificación de toda condición afectivo-erótica distinta de la heterosexualidad con un desvío patológico de la conducta. El humor popular da cuenta de esto con los chistes y el escarnio constante que se hace de los miembros de la comunidad gay: siempre los blancos fáciles de la comedia. La discriminación es la norma y la interiorización de dicha segregación entre las víctimas suele ser el mecanismo de compensación entre quienes no tienen más remedio que buscar guarecerse emocionalmente en un clima de hostigamiento constante.

Como se verá en el próximo apartado, el humor es en Bohórquez una de las más potentes estrategias de reivindicación y de denuncia. El blanco de estos dardos es la autoridad que encarna en múltiples avatares, todos ellos represivos y protectores de una moral tradicionalista: los textos sagrados, la autoridad policial, la censura social o las costumbres. Es de hacer notar que, en este proceso de cuestionamiento de la autoridad, no solamente lo temático es importante, sino también lo formal, en concreto, la construcción o formulación genérica de los poemas. El poeta sonorense posee un vasto conocimiento de la tradición literaria occidental, lo que le permite ejecutar con notable destreza y maestría su venganza literaria sobre la página.

La tradición literaria se vuelve contra la rigidez y estrechez de miras de sus más conspicuos defensores. En las manos del poeta-justiciero, la retórica del Siglo de Oro, la cantiga y la poesía precolombina se ven revitalizadas por la creatividad desaforada de Bohórquez. Culto y mordaz, el poeta rompe con los tabúes impuestos al lenguaje por las consideradas "buenas costumbres" y habla con absoluta claridad de los coitos entre varones, del sexo oral y anal, 
de la satisfacción sexual que le provocan los encuentros casuales con sus amantes. Fuente de saber, el placer es para Bohórquez una vía de iniciación en los poderes de la vida; por eso la resistencia es radical, porque reclama un espacio de libertad para aprehender la realidad desde un modo particular en lo que se hace y se dice. La poesía es el complemento de esa comprensión sensual de la existencia: el inventario de goces - y dolores - es un camino de ascenso hacia la experiencia cumbre: el orgasmo como íntima e irreductible verdad del estar vivos.

\section{Estructura, humor y juego}

Resulta claro, después de haber revisado de manera general el carácter estilístico, temático y político de Digo lo que amo, que su autor es un artista plenamente consciente de su oficio: el libro no es una simple acumulación aleatoria de poemas sino una estructura plenamente definida que obedece a una intencionalidad y un deseo creativos innegociables. Se trata de un texto consciente cuya funcionalidad se encuentra determinada por dos polos aparentemente antagónicos: la crítica y la celebración. Se critica lo que oprime el derecho a celebrar desde la carne la experiencia humana y el deleite de las exploraciones sexuales que uno apetece. La pluma de Bohórquez demuestra con estos poemas cómo la pasión por la creación debe ser esclava del trabajo arduo y la disciplina: no basta sentir, además es necesario saber, querer y no renunciar nunca.

Existe en la obra del poeta sonorense un carácter analógico que deseo destacar: la resolución actual de la pugna entre la tradición y la renovación. Al respecto, el profesor Mauricio Beuchot afirma en su Tratado de hermenéutica analógica:

Innovación no es solo romper con una tradición, sino tratar de aportar algo a la tradición misma, aplicar acertada y adecuadamente el mensaje que contiene el texto en cuestión al momento actual, eso es, interpretar desde la vida del intérprete (efectuar la aplicación, como decían ya en el sigo XVIII 
Rambach y Ernesti). (66)

Si el filósofo mexicano lleva algo de razón, estamos llamados a comprender que el Abigael-poeta reutiliza las formas de la tradición literaria (occidental y prehispánica) para abordar temáticas de actualidad, con el fin de provocar con ello un extrañamiento estético que vuelva visible una situación de opresión y, por tanto, de injusticia. Al mismo tiempo, el yo-poeta se inscribe en esa tradición, la honra y la renueva: abre camino ahí donde solo había repetición y falta de sentido; la renovación es revigorización o recarga semántica de una estructura poética decadente.

Con respecto a este apartado, podemos ver claramente dos vertientes estructurales claras: la tradición medieval y del Siglo de Oro, y la retórica poética del mundo precolombino, específicamente náhuatl, al menos como podemos reconocerlo en las traducciones del padre Ángel María Garibay. Un poema como "Cargo" es clara muestra de lo primero:

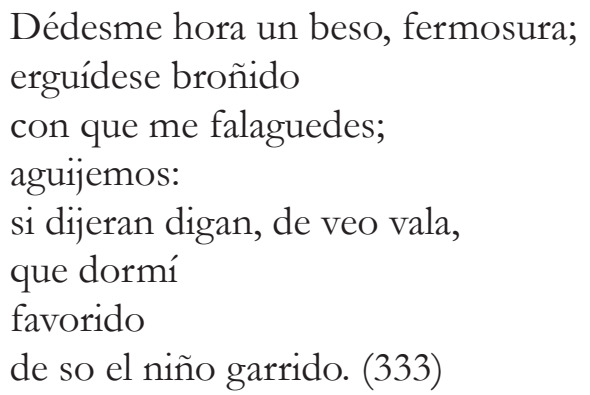

En esta breve muestra puede bien apreciarse la reapropiación de la tradición trovadoresca del medioevo y del amor cortés de las cantigas de amor, en las que un yo poético enfebrecido de amor canta las delicadas maravillas de su dama. Esto es particularmente importante porque Bohórquez entiende bien que, en dicha tradición, el tú poético admite una ambivalencia genérica masculino-femenino que le sirve bien para su estética camp igualmente travestida y que rehúsa el binomio masculino-femenino como algo predeterminado e inquebrantable. Esto ejemplifica de una manera puntual cómo alguien es capaz de comprender una tradición, adaptarla a las cir- 
cunstancias del momento presente y rejuvenecer con ello una forma poética condenada durante siglos a las antologías.

En cuanto a la recuperación de las estructuras prehispánicas, el poema "Tlamatini" se apropia de dicho tono y estilo sin renunciar a la parodia.

$[\mathrm{H}]$ a cesado su canto.

nos ataviamos, nos enriquecemos

con sus terrenas pertenencias: cíngulos, crótalos, diálogos, lenguas de obsidiana, una calle.

flores cogía el de coyohuácan, pajaros cogía: ¿pájaro en mano puede haber quien se sienta sin dicha sobre la tierra? Oh, pluma, la más pluma, dice: (344)

Lo paródico en este poema sirve al humor, crea un pastiche o refundación de un tema o género que le antecede y con ello busca provocar la risa mediante el clásico recurso de la ironía: Novo, a quien refiere el poema, es el sapiente, pero también y lejos de la solemnidad del tono general del poema, es el que se regodea entre flores, es el que coge pájaros y por lo tanto no puede sentirse sin dicha; las referencias a los genitales masculinos son tan evidentes que no precisan aclaración ninguna. Sobre la parodia o pastiche, Beristáin en su diccionario define: "obra original construida, sin embargo, a partir de la codificación de elementos estructurales tomados de otras obras" (387). De nuevo a cuenta esta idea antes señalada de la apropiación virtuosa y mordaz de una tradición literaria que se conoce tan bien que puede ser perfectamente objeto de la reinvención lúdica con fines satíricos.

Existe en Digo lo que amo una estética grandilocuente, exagerada, de aspaviento y risotada. Estamos en presencia de una estética dionisiaca, desaforada y luminosa en la que la vitalidad se escapa por todos lados. Lejos de la reflexión existencial densa y de tintes filosóficos, esta poesía embona con la vida, hurga en la herida y asume sin pudores una identidad propia que no admite ser sometida a 
reprimenda o corrección ninguna. La rebelión estética del decir lo que se es implica romper con el lenguaje que utilizan los autoritarios; contra la jerga esclerótica de los púlpitos será siempre conveniente recurrir al humor, al juego, la burla y la creatividad, es decir, al ejercicio radical de la libertad para señalar precisamente a quienes buscan acotar esa misma libertad a todos los que no piensan, no sienten o no son como ellos mismos. Por eso, detrás de un libro como Digo lo que amo, es posible definir una ética de renovación en el decir y en el convivir: se recupera la palabra para poder decir sin rubores lo que más nos hace falta. Lejos de ser una frivolidad, un mero "chiste", esta reivindicación es un asunto de vida o muerte.

Resumiendo, el humor como eje fundamental de este poemario es animado a su vez por una voluntad de juego, es decir, de movilización creativa y exploratoria de las posibilidades de expresión poética. En este sentido, es posible perfectamente realizar una analogía entre esto último y la experiencia sexual como manifestación creativa e igualmente lúdica. El yo poético parece expresar las dos caras de una misma moneda: al amar y al crear estamos jugando y estamos celebrando nuestra existencia.

\section{Yo, el otro, el mundo}

La expresión poética implica una conciencia de ser y estar en el mundo: todo poema es a un mismo tiempo una reacción y un testimonio. El yo que somos es una condición existencial que deviene, es decir, que evoluciona en el contacto directo con la realidad; entre las experiencias más determinantes en la formación de nuestra conciencia se encuentra el amor, que lejos de ser un ideal, es una práctica cotidiana, encarnada y sensible que los seres humanos reconocemos como lo más propiamente nuestro: el abrirnos a los demás para dejarnos tomar, para trascender la comunicación y conseguir, así fuera por un instante, la comunión.

A lo largo de estas páginas he intentado dejar en claro que considero al ser humano como un ser consciente y encarnado, atado trágicamente a su temporalidad y, al mismo tiempo, poseedor de 
una sensibilidad esencial sin la que su existencia carece de propósito alguno. La pantalla de los sentidos se abre a la reproducción cambiante de la realidad, síntesis siempre compleja, estado momentáneo del saber sobre el que se monta nuestra vida toda. En el caso de Digo lo que amo, las sensaciones son la justificación principal de ese amor que se enuncia, pero no como ideal o como pretexto, sino como su condición esencial: amar es tocar, sorber, olfatear, es decir, dialogar sin palabras con esa carne viviente y sintiente que se ama. Como bella y apasionadamente lo recuerda Michel Serres: "Loving a body, that rare special thing; no other volume on the surface of the planet has more value. Love confuses us; two chambers pouring together" (170).

Entre las sensaciones y la conciencia, un puente de palabras. El lenguaje posee un carácter analógico que preserva experiencia y psiquismo, es decir, abstracción pura. Sin la palabra la experiencia sería inútil, bestialidad vacua que nada dice y hacia ninguna parte va; por otra parte, sin la sensación la palabra es logos, es decir, materia de la divinidad, acto puro, algo que no nos incumbe en modo alguno. La maravilla de los poemas de Bohórquez, y por extensión de la poesía, es que nos permite experimentar ambos polos en su lectura: se degusta con el oído, se palpa con la voz, se nutre el espíritu con los poderes creativos de la imaginación. La poesía es un arte que se dice a sí mismo, que es consciente de sí mismo: es un milagro. George Steiner apunta con precisión en este sentido:

Gradually this ambivalence in the genius of language, this notion of god-rivaling, therefore potentially sacrilegious character of the act of the poet, becomes one of the current tropes of western literature. From Medieval Latin poetry to Mallarmé and Russian Symbolist verse, the motif of the necessary limitations of the human word is a frequent one. (39)

La voz del poeta, enmascarada en ese yo poético, desea y expresa el deseo: proyecta hacia el futuro lo que ha sido o relata desde un tiempo presente detenido como un testimonio vivo de su amor. El deseo encarna una ética propia, que es la de tomar y ser tomado: 
existe una clara condición de diálogo e igualdad en el campo de las prácticas amatorias. No existe, contrario a lo que podría dictar la opinión extendida, una relación de dominio y sumisión, y el propio sonorense lo reconoce en unos versos de gran belleza:

Luego estuvimos mucho tiempo mudos, vencedores vencidos acribillados, cómplices sobre las pajas ásperas, él junto a mí, sonando todavía y yo, mi cara sobre sus genitales de salvaje pureza. (351)

Los amantes son coautores de sus obras amatorias: triunfan y son derrotados al unísono. La vida es diálogo que termina en silencio porque todo se ha dicho ya, porque el vaso de la significación se ha colmado y el éxtasis es un paraíso que precisa ser compartido.

Es el otro, el que entra en escena, el que, como yo, es activo: puede asirme y sentirme. Al tocar soy tocado. Esta singularidad, propia del tacto (y en cierta forma también del gusto, como se mencionó), hace del roce de pieles un diálogo en sentido estricto. La soledad se rompe y la unión, necesariamente momentánea, crea un vínculo indivisible, de fusión y comprensión únicas: solo somos verdaderamente cuando somos sentidos.

Ahora bien, con todo lo anterior podemos concluir que Digo lo que amo, esencialmente, se yergue como un intento de legitimación del ser como agente, es decir, en su carácter existencial. Busca justificar la vida en todos sus aspectos, desde el amor y contra el odio. Decir lo que se ama es afirmar, pero también negar aquello que amenaza la libertad total que el poeta reclama para sí mismo y sus amantes. La centralidad temática del texto la ocupa el amor, sin duda, porque es un amor condenado por la costumbre conservadora, porque es asumido por la sociedad como una afrenta que debe señalarse e incluso combatirse. Es además un amor encarnado, que se muestra en sus rituales eróticos y en la necesidad de un cuerpo que lo ponga en práctica. En este sentido es un amor vitalísimo que intenta ocupar la totalidad del ser, lejos de las idealizaciones y enmascaramientos; pero también es verdad que en ese mundo 
delineado por Bohórquez en este compendio poético, existen también elementos - ya abordados en este estudio- que no resultan menos importantes para la comprensión de la obra; me refiero en específico a dos elementos temáticos-estructurales: la injusticia social (no limitada a la homofobia) y la tradición, ese basamento sobre el que tan sólidamente se apoya el también llamado poeta mayor del desierto. Este es el mundo en el que el otro y el yo trafican sus caricias y establecen un sistema de ofensiva: el de las palabras que devienen de poema en poema por los ramajes de las genealogías de nuestra tradición hispánica.

El amor se ha dicho y el eco de sus voces nos queda en la conciencia propia como testimonio de vitalidad y responsabilidad con la sociedad y con la poesía. La obra de Bohórquez se abre al mundo desde la intimidad testimonial para rendir cuentas de una vida en la que el adeudo con la pasión es al mismo tiempo compromiso con la denuncia; y en su aspiración de totalidad, está una de sus más grandes virtudes. Comprender la vida y comprender el texto pasa necesariamente por los sentidos: mutilar esta vía es condenarnos a una lamentable confusión de falsas verdades y verdaderos equívocos; en este sentido, Digo lo que amo aporta en su libertad radical al entendimiento de nuestra experiencia humana y solo por eso vale la pena su lectura y su disfrute. La poesía, conviene no olvidarlo, no solo habla de la vida, sino que además es parte de la construcción de esa misma vida, que al cantar se vuelve más alegre, rica y generosa.

\section{Bibliografía}

Beristáin, Helena. Diccionario de retórica y poética. Porrúa, 1995.

Beuchot, Mauricio. Tratado de hermenéutica analógica: hacia un nuevo modelo de interpretación. Itaca, 2000.

Bohórquez, Abigael. Digo lo que amo. Editado por Gerardo Bustamante Bermúdez, Universidad Autónoma de la Ciudad de México, 2015.

- Poesía reunida e inédita. Editado por Gerardo Bustamante Bermúdez, Instituto Sonorense de Cultura, 2016. 
Bousoño, Carlos. Teoría de la expresión poética. Gredos, 1956.

Brown, Norman O. "Apocalypse: The Place of Mystery in the life of the Mind." Interpretation: the poetry of meaning, editado por Stanley Romaine Hopper y David L. Miller, Harbinger Books, 1967, pp. 7-13.

Gadamer, Hans-Georg. Verdad y método. Sígueme, 1999. . Verdad y método II. Sígueme, 2006.

Hopper, Stanley Romaine, y David L. Miller, editores. Interpretation: the poetry of meaning Philosophical, Religious, and Literary Inquiries into the Expression of Human Experience Through Language. Harbinger Books, 1967.

Kearney, Richard, y Brian Treanor, editores. Carnal hermeneutics. Fordham University, 2015.

Ricœur, Paul. Freedom and nature: the voluntary and involuntary. Northwestern University, 1966.

. Interpretation theory: discourse and the surplus of meaning. Texas Christian University, 1976.

Serres, Michel. The five senses: a philosophy of mingled bodies (I). Continuum, 2009.

Smith, Robert Rowland. On Modern Poetry: from Theory to Total Criticism. Continuum, 2012.

Steiner, George. Language and silence: essays on language, literature, and the inbuman. Atheneum, 1970. 